\title{
The reactivity of cokes in Boudouard-Bell reactions in the context of an Ergun model
}

\author{
Andrzej Mianowski ${ }^{1} \cdot$ Tomasz Radko $^{1} \cdot$ Tomasz Siudyga $^{1}$
}

Received: 22 October 2014 / Accepted: 3 May 2015/Published online: 28 May 2015

(C) The Author(s) 2015. This article is published with open access at Springerlink.com

\begin{abstract}
In previous studies, a kinetic equation based on the Ergun mechanism and concept presented in 1956 was applied to Boudouard-Bell reactions for granular coke (1-3 mm) in the temperature range $T=1173-1423 \mathrm{~K}$. In contrast to several other works on this subject, the proposed equation was based on only three kinetic constants: $k_{1}$, the rate constant for the Boudouard reaction; $k_{-1}$, the rate constant for the Bell reaction; and $k_{3}$, which is related to the oxy-carbon decomposition and $\mathrm{CO}$ desorption process. The dependence of these constants on temperature allows certain values characteristic of the aforementioned processes to be calculated, including activation energy of gasification reaction, enthalpy of disproportionation reaction of gasification and activation energy of desorption process. When $k_{-1}>0$, i.e., the Bell reaction and inhibitory effects occur, the kinetic constant $k_{3}$ can be determined using a portion of the experimental $[\mathrm{CO}]$ versus time data normalized to the maximum contribution of $\mathrm{CO}$ in the outlet gases.
\end{abstract}

Keywords Boudouard-Bell reactions · Gasification · Kinetics · Coke reactivity

Electronic supplementary material The online version of this article (doi:10.1007/s10973-015-4761-3) contains supplementary material, which is available to authorized users.

Tomasz Siudyga

tomasz.siudyga@polsl.pl

1 Faculty of Chemistry, Silesian University of Technology, Krzywoustego 6, 44100 Gliwice, Poland

\section{List of symbols}

$\alpha$

$C_{\mathrm{f}}$

$C_{\mathrm{cb}}$

$C_{\mathrm{t}}$

$\mathrm{C}(\mathrm{O})$

$C_{0}$

C, $C_{1}$

$\left[\mathrm{CO}_{2}\right],[\mathrm{CO}]$

$[\mathrm{CO}]_{\mathrm{m}}$

E

$E_{-1}$

$E_{\text {des }}$

F

$\Delta_{\mathrm{r}} H$

$k$

$k_{1}$

$k_{-1}$

$k_{3}$

K

$N$

$\Theta$

$r^{2}$
Conversion degree of $\mathrm{CO}_{2}, 0 \leq \alpha \leq 1$

Free carbon sites

Carbon as a carbon black

Total number of active carbon sites Carbon sites occupied by oxygen (oxycarbon), acc. Ergun [1]

Combinations of kinetic constants in case when $k_{3}=0$

Combinations of kinetic constants

Mole fraction, respectively, $\mathrm{CO}_{2}$ and $\mathrm{CO}$,

$0 \leq\left[\mathrm{CO}_{2}\right] \leq 1,0 \leq[\mathrm{CO}] \leq 1$

Maximum value of mole fraction $\mathrm{CO}$, $0 \leq[\mathrm{CO}]_{\mathrm{m}} \leq 1$

Activation energy of gasification reaction (Boudouard reaction), $\mathrm{J} \mathrm{mol}^{-1}$

Activation energy of disproportionation reaction (Bell reaction), $\mathrm{J} \mathrm{mol}^{-1}$

Activation energy of desorption process, $\mathrm{J} \mathrm{mol}^{-1}$

Statistical test $F$

Enthalpy of reversible reaction of gasification (1), $\mathrm{J} \mathrm{mol}^{-1}$

Factor of proportionality in Eq. (9)

Kinetic constant of gasification reaction

(Boudouard reaction), time ${ }^{-1}$

Kinetic constant of disproportionation reaction (Bell reaction), time ${ }^{-1}$

Kinetic constant of desorption process, time $^{-1}$

Experimental constant of reaction, Eq. (6)

Number of measurements/observations

Fractional surface coverage of active sites acc. (5)

Determination coefficient, $0 \leq r^{2} \leq 1$ 


$\begin{array}{ll}\dot{R} & \text { Rate of complex process, time } \\ R^{2} & \begin{array}{l}\text { Determination coefficient in nonlinear } \\ \text { regression, } 0 \leq R^{2} \leq 1\end{array} \\ \rho^{2} & \begin{array}{l}\text { Determination coefficient in equation } \\ \text { without intercept, } 0 \leq \rho^{2} \leq 1\end{array} \\ \text { sl } & \text { Significance level } \\ T & \text { Absolute temperature, } \mathrm{K} \\ v & \text { Rate of reaction/process, time } \\ \mathrm{VM}^{-1} & \text { Volatile matter in dry and ash-free state, } \% \\ \tau & \text { Time, } \mathrm{s} \\ x & \text { Conversion degree of solid phase, } \\ & 0 \leq x \leq 1\end{array}$

\section{Subscripts \\ des Desorption process \\ $m \quad$ At the maximum \\ $r \quad$ Reaction}

\section{Introduction}

\section{Ergun considerations and their consequences}

Assuming an Ergun mechanism gasification with carbon dioxide [1] takes the form of the following reversible reaction, i.e., where $k_{-1} \equiv k_{1}^{\prime}$ and $\mathrm{C}(\mathrm{O}) \equiv \mathrm{C}_{\mathrm{O}}$ :

$\mathrm{CO}_{2}+\mathrm{C}_{\mathrm{f}} \underset{k_{-1}}{\stackrel{k_{1}}{\longrightarrow}} \mathrm{CO}+\mathrm{C}(\mathrm{O})$.

The $\mathrm{C}(\mathrm{O})$ decomposition and $\mathrm{CO}$ desorption process (referred to throughout as the desorption process) can be described as:

$\mathrm{C}(\mathrm{O}) \stackrel{k_{3}}{\longrightarrow} \mathrm{CO}+\mathrm{C}_{\mathrm{f}}$.

Given the assumption that:

$\mathrm{C}_{\mathrm{t}}=\mathrm{C}_{\mathrm{f}}+\mathrm{C}(\mathrm{O})$

one can obtain the equation:

$\frac{\mathrm{d} \Theta}{\mathrm{d} \tau}=k_{1}\left[\mathrm{CO}_{2}\right](1-\Theta)-k_{-1}[\mathrm{CO}] \Theta-k_{3} \Theta$

where

$\Theta=\frac{\mathrm{C}(\mathrm{O})}{\mathrm{C}_{\mathrm{t}}}$.

For Eq. (4) to hold, according to [1, 2], two distinctive characteristics must be defined.

a) The experimental equilibrium constant of the reversible reaction, which is the analog of the thermodynamic equilibrium constant, can be determined from [3] as:
$K=\frac{[\mathrm{CO}] \Theta}{\left[\mathrm{CO}_{2}\right](1-\Theta)}=\frac{k_{1}}{k_{-1}}=$ id e $m$.

b) This system has the requirement of the steady-state assumption where

$\frac{\mathrm{d} \Theta}{\mathrm{d} \tau}=0$.

One can determine the value of $\Theta$, and from Eqs. (4) and (7), the well-known Langmuir-Hinshelwood equation $(\mathrm{L}-\mathrm{H})$ can be obtained [4-15].

Condition (7) eliminates the inconvenience of simultaneous occurrence of values in Eq. (4) that are related to the composition of the gas ([CO], $\left.\left[\mathrm{CO}_{2}\right]\right)$ and the solid phase $\left(\Theta=\mathrm{C}(\mathrm{O}) / \mathrm{C}_{\mathrm{t}}\right)$ without invoking their analytical relationship. Finally, $\Theta$ can be obtained as:

$\Theta=k_{1} \frac{\left[\mathrm{CO}_{2}\right]}{k_{1}\left[\mathrm{CO}_{2}\right]+k_{-1}[\mathrm{CO}]+k_{3}}$.

The left side of Eq. (8) can be expanded by connecting the Boudouard-Bell (B-B) reactions with the partial oxidation process that occurs in the presence of oxygen (POX-bis) [16-19] or by introducing secondorder terms including the partial pressure of $\mathrm{CO}_{2}$ $[16,20]$.

Other interpretations of Eq. (8) rely on assigning a rate of the process comprising the chemical reaction and the desorption to the left side of Eq. (8) and on introducing relationships between the products of the concentrations of the components in the gas phase and particular constants to the right side of Eq. (8).

The left-hand side of Eq. (8) is most often presented in a simple form as:

$\dot{R}=k \cdot \Theta$

where $k$ is a proportionality coefficient and $\dot{R}$ is the rate of the complex process expressed as the conversion degree of the solid phase $x$ in time: $\mathrm{d} x / \mathrm{d} \tau[4,12,13], \mathrm{d} x /(1-x) \mathrm{d} \tau$ $[8,13,15,21]$ in $\left[\right.$ time $\left.^{-1}\right]$ or with respect to the surface area (specific) as the intrinsic reaction rate $[6,15]$ in $\left[\mathrm{g} \mathrm{m}^{-2} \mathrm{~s}^{-1}\right]$.

\section{Aim of the work}

Based on the general form of Eq. (4), a new kinetic approach to the $\mathrm{B}-\mathrm{B}$ reaction is proposed as a result of reflections on the mechanism of this reaction and recent studies on the stability of the complex $\mathrm{C}(\mathrm{O})$, presented in [21], among others. In these presented considerations on 
B-B reaction kinetics, a novel approach was used as a conceptual framework to describe the complex process, specifically incorporating independence from the chemical reaction and desorption process.

\section{A kinetic approach to analyzing mechanism (1) and (2)}

\section{General equation}

From a kinetic point of view, $\mathrm{CO}_{2}$ gasification monitored in the outlet gas composition can be described as a mole fraction of carbon monoxide as well as by the conversion degree of $\mathrm{CO}_{2}$ introduced into reaction system. The latter value does not require defining all of the products formed in the reaction/process, and for only two components $(\mathrm{CO}$ and $\mathrm{CO}_{2}$ ), it leads to the condition:

$\left[\mathrm{CO}_{2}\right]+[\mathrm{CO}] \equiv 1$.

As in [22], the conversion degree can be expressed as:

$\alpha=\frac{1-\left[\mathrm{CO}_{2}\right]}{1+\left[\mathrm{CO}_{2}\right]}=\frac{[\mathrm{CO}]}{2-[\mathrm{CO}]}$.

Based on our own experiences, it was demonstrated that the use of $\mathrm{CO}$ mole fraction in these calculations is more reliable than using the conversion degree of $\mathrm{CO}_{2}$. Use of $\mathrm{CO}$ mole fractions makes interpretation of the kinetic constants and their relationships more credible. Calculations were performed for these two possibilities, i.e., using both $\alpha$ and [CO], but further considerations are presented only for mole fraction of $\mathrm{CO}$. In accordance with the point of view expressed in [1] and its development, the rate of reaction/process was assumed to be the result of two rates: the chemical reaction and the desorption process:

$v=v_{\mathrm{r}}-v_{\mathrm{des}}$.

Based on the experimental results, it can be assumed that the desorption process is the limiting stage of the complex process of gasification [4, 10, 23], and therefore, Eq. (12) can be presented as:

$\frac{\mathrm{d}[\mathrm{CO}]}{\mathrm{d} \tau}=v_{\mathrm{r}}-k_{3}[\mathrm{CO}]$.

The rate of reversible chemical reaction is [24, 25]:

$v_{\mathrm{r}}=\frac{\mathrm{d}[\mathrm{CO}]_{\mathrm{r}}}{\mathrm{d} \tau}=k_{1}\left(1-[\mathrm{CO}]_{\mathrm{r}}\right)-k_{-1}[\mathrm{CO}]_{\mathrm{r}}$.

Solving Eq. (14) leads to:

$[\mathrm{CO}]_{\mathrm{r}}=\frac{k_{1}}{k_{1}+k_{-1}}\left[1-\exp \left(-\left(k_{1}+k_{-1}\right) \tau\right)\right]$,

which, after differentiation, is a function of time only: $v_{\mathrm{r}}=k_{1} \exp \left[-\left(k_{1}+k_{-1}\right) \tau\right]$.

In the literature concerning the $\mathrm{B}-\mathrm{B}$ reaction, one can often encounter a kinetic constant marked as $k_{2}$, which is often identical to the constant marked as $k_{-1}[5,13-15,21]$. By combining Eq. (16) and Eq. (13), a differential equation is obtained, which eliminates the necessity of determining the boundary conditions for individual stages of the complex process in Eq. (12):

$\frac{\mathrm{d}[\mathrm{CO}]}{\mathrm{d} \tau}=k_{1} \exp \left[-\left(k_{1}+k_{-1}\right) \tau\right]-k_{3}[\mathrm{CO}]$.

Equation (17) can be resolved using the constant variance method. Initially, Eq. (13) is solved for $v_{\mathrm{r}}=0$, and after that, variability of the integration constant is assumed. For the initial condition: $[\mathrm{CO}]=0$ for $\tau=0$, the following relationship is obtained:

$[\mathrm{CO}]=\frac{k_{1}}{k_{1}+k_{-1}-k_{3}}\left[\exp \left(-k_{3} \tau\right)-\exp \left(-\left(k_{1}+k_{-1}\right) \tau\right)\right]$.

For $k_{3}=0$, i.e., the desorption process does not occur, Eq. (18) simplifies to Eq. (15), which is valid for reversible reactions $[22,24]$. If the combination of kinetic constants in Eq. (18) is denoted as $C$ :

$C=\frac{k_{1}}{k_{1}+k_{-1}-k_{3}}$,

then it is easy to observe that the physical meaning of Eq. (18) implies the inequality:

$k_{1}+k_{-1}>k_{3}$.

Further analysis using the combined form of the kinetic constants (19) in Eq. (18) leads us to the case where $C \leq 1$, which implies another inequality:

$k_{-1} \geq k_{3}$.

However, the case with $C>1$ suggests that the kinetic constant $k_{-1}=0$; hence, the reaction proceeds irreversibly, and combination of the kinetic constants (19) reduces to the form:

$C=\frac{k_{1}}{k_{1}-k_{3}}>1$ for $k_{3}>0$.

From Eq. (18) and the assumption that $\mathrm{d} \alpha / \mathrm{d} \tau=0$, the time at which the relation in Eq. (18) exhibits a maximum value can be determined from:

$\tau_{\mathrm{m}}=\frac{\ln \frac{k_{1}+k_{-1}}{k_{3}}}{k_{1}+k_{-1}-k_{3}}$.

After the introduction of $\tau_{\mathrm{m}}$ defined by Eq. (23) into Eq. (18), one can obtain an equation determining the maximum contribution of $\mathrm{CO}$ : 
$[\mathrm{CO}]_{\mathrm{m}}=\frac{k_{1}}{k_{3}}\left(\frac{k_{3}}{k_{1}+k_{-1}}\right)^{\frac{k_{1}+k_{-1}}{k_{1}+k_{-1}-k_{3}}}$.

In the particular case when $k_{-1}=0$, Eq. (24) simplifies to the form:

$[\mathrm{CO}]_{\mathrm{m}}=\left(\frac{k_{3}}{k_{1}}\right)^{\frac{\mathrm{k}_{3}}{\mathrm{k}_{1}-\mathrm{k}_{3}}}$.

\section{Equation of desorption}

Continuing analysis of a complex gasification process based on Eq. (13), the following interpretation can be made. If the reaction reaches a value consistent with Eq. (23), one can assume that the end of the chemical reaction, i.e., $v_{\mathrm{r}}=0$, has been reached. In this scenario, one can observe that the continued course of the gasification is dominated by the desorption process. Resolving Eq. (13) at the corresponding limits of integration:

$\int_{\alpha_{\mathrm{m}}}^{\alpha} \frac{\mathrm{d}[\mathrm{CO}]}{[\mathrm{CO}]}=-k_{3} \int_{\tau_{\mathrm{m}}}^{\tau} \mathrm{d} \tau$,

the following equation is obtained:

$[\mathrm{CO}]=[\mathrm{CO}]_{\mathrm{m}} \exp \left[-k_{3}\left(\tau-\tau_{\mathrm{m}}\right)\right] \quad$ for $v_{\mathrm{r}}=0$.

Substituting into Eq. (27) the values for $[\mathrm{CO}]_{\mathrm{m}}$ from formula (24) and $\tau_{\mathrm{m}}$ from formula (23) leads to:

$[\mathrm{CO}]=\mathrm{C}_{1} \exp \left(-k_{3} \tau\right) \quad \tau>\tau_{\mathrm{m}} \quad$ where $\quad C_{1}=\frac{k_{1}}{k_{1}+k_{-1}}$.

Analysis of Eq. (28) requires the selection of a subset of the experimental data, i.e., rejection of data where $\tau<\tau_{\mathrm{m}}$. For the initial requirement where $\tau=0$, an extrapolated value of the fraction $C_{1}$ is obtained, which has to be $\leq 1$.

A linear relation (28) in the form:

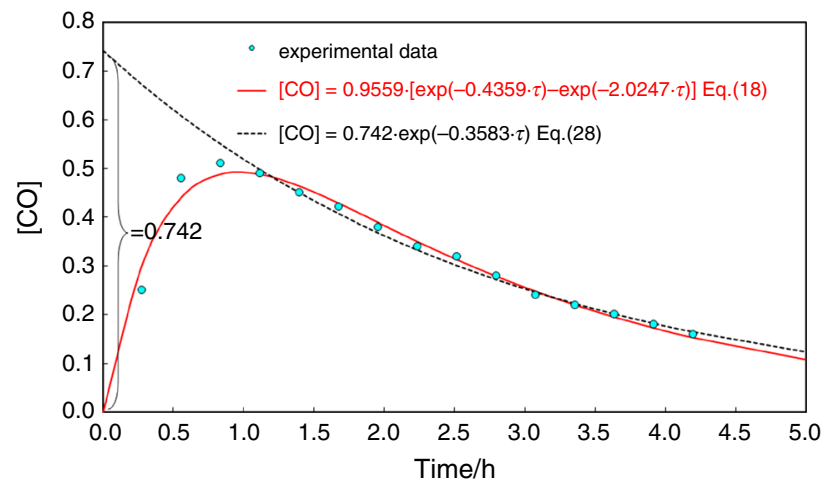

Fig. 1 Comparison of (18) and (28) models with experimental data for a domestic coke sample (sample No. 9 in Table S1) $\ln [\mathrm{CO}]=\ln C_{1}-k_{3} \tau$

fulfills an auxiliary function, but it is very important in the analysis of the kinetics of the gasification reaction/process according to (1) and (2). This equation makes possible to compare the two concepts of directly determining the kinetic constant $k_{3}$ and the remaining $k_{1}, k_{-1}$ relation. Figure 1 illustrates the relationship of the model (18) with (28).

\section{Experimental and results}

Analysis of the application of Eq. (18) and Eq. (28) was performed using data presented in manuscript [26]. This work concerns the studies on $\mathrm{CO}_{2}$ gasification of typical cokes produced in Poland. There were 11 test samples of blast-furnace and domestic cokes under isothermal conditions at one temperature $T=1273 \mathrm{~K}$ and two selected samples at six temperatures ranging from 1173 to $1423 \mathrm{~K}$ with steps $\Delta T=50 \mathrm{~K}$, based on the Geneva method [27]. The basic reactivity test is based on the gasification of a 7-g coke sample with a grain size of 1-3 $\mathrm{mm}$ at temperature $1273 \mathrm{~K}$. After $15 \mathrm{~min}$, based on gaseous product composition, kinetic constants are determined using the equation given in [27] and [22]. The basic test [26] was modified by extending the time of gasification of the test samples, and the current analysis of gaseous products composition was applied. Results obtained in [26] are presented in Supplementary Materials-Tables S1 and S2.

Results of our calculations using these experimental data from [26] are shown in Tables 1,2 and 3. Table 1 contains the kinetic constants determined for the 11 coke samples under isothermal conditions, and Tables 2 and 3 contain the kinetic constants of two selected coke samples depending on time and temperature of the gasification reaction for blast-furnace coke (high quality) and domestic coke (low quality), respectively.

The calculations according to Eq. (18) were performed by Marquardt method and omitting the coordinate [0, 0], which advantageously increases the coefficient $R^{2}$ and $r a$ tio, which is an analog of the $F$ test.

\section{Coke quality}

Based on the data presented in Table 1, variation in the determination coefficient is observed in the range $R^{2}=0.84-0.97$, which for $N=15$ measurements satisfies the criteria for accepting the validity of Eq. (18). Moreover, at the temperature $T=1273 \mathrm{~K}$ under which these measurements were taken, the combination of kinetic constants (19) satisfies the constraint $C \leq 1$. Therefore, 
Table 1 Kinetic constants calculated for analyzed coke samples

\begin{tabular}{|c|c|c|c|c|c|c|c|}
\hline Coke no. & $\begin{array}{l}C \\
\text { acc. (18) }\end{array}$ & $k_{3}, \mathrm{~h}^{-1}$ & $k_{1}+k_{-1}, \mathrm{~h}^{-1}$ & $R^{2}$ & Ratio & $\begin{array}{l}k_{1}^{*}, \mathrm{~h}^{-1} \\
\text { acc. }(20)\end{array}$ & $k_{-1}, \mathrm{~h}^{-1}$ \\
\hline 1 & 0.7769 & 0.3065 & 2.0090 & 0.9769 & 2876.9 & 1.3227 & 0.6863 \\
\hline 2 & 0.7680 & 0.3875 & 2.1396 & 0.9633 & 1628.9 & 1.4070 & 0.7326 \\
\hline 3 & 0.8480 & 0.3847 & 1.3477 & 0.9341 & 827.4 & 0.8166 & 0.5311 \\
\hline 4 & 0.8733 & 0.3785 & 2.1295 & 0.9392 & 677.0 & 1.5291 & 0.6004 \\
\hline 5 & 0.6580 & 0.3446 & 1.9677 & 0.9497 & 1028.9 & 1.0680 & 0.8997 \\
\hline 6 & 0.9385 & 0.4174 & 1.6527 & 0.9605 & 1106.0 & 1.1593 & 0.4934 \\
\hline 7 & 0.8809 & 0.3955 & 1.8790 & 0.9211 & 510.7 & 1.3068 & 0.5722 \\
\hline 8 & 0.7970 & 0.3429 & 1.9849 & 0.8887 & 416.2 & 1.3087 & 0.6762 \\
\hline 9 & 0.9559 & 0.4359 & 2.0247 & 0.9728 & 1313.6 & 1.5187 & 0.5060 \\
\hline 10 & 0.7743 & 0.3606 & 1.9056 & 0.9307 & 681.0 & 1.1960 & 0.7093 \\
\hline 11 & 0.7045 & 0.2779 & 1.9837 & 0.8569 & 417.4 & 1.2017 & 0.7820 \\
\hline
\end{tabular}

$* k_{1}=C \cdot\left(k_{1}+k_{-1}-k_{3}\right)$, sum of $\left(k_{1}+k_{-1}\right)$ is known

Table 2 Kinetic constants for blast-furnace coke-sample No. 3 in Table S2

\begin{tabular}{llllllrr}
\hline Temperature/K & $\begin{array}{l}C \\
\text { acc. (18) }\end{array}$ & $k_{3}, \mathrm{~h}^{-1}$ & $k_{1}+k_{-1}, \mathrm{~h}^{-1}$ & $R^{2}$ & Ratio & $\begin{array}{c}k_{1}^{*}, \mathrm{~h}^{-1} \\
\text { acc. }(20)\end{array}$ \\
\hline 1173 & 0.1667 & 0.4074 & 1.9790 & 0.8564 & 232.8 & 0.2620 \\
1223 & 0.5284 & 0.4100 & 1.2904 & 0.8618 & 294.7 & 0.4652 \\
1273 & 0.8470 & 0.3844 & 1.3489 & 0.9341 & 827.4 & 0.8169 & 0.8252 \\
1323 & 1.6968 & 0.5272 & 1.3028 & 0.9501 & 733.7 & 1.3028 & 0.5020 \\
1373 & 1.2619 & 0.4739 & 2.0806 & 0.9784 & 1418.3 & 2.0806 & 0 \\
1423 & 6.5366 & 0.9501 & 1.3268 & 0.9896 & 1546.6 & 1.3268 & $0 *$ \\
\hline
\end{tabular}

* For $C>1, k_{-1}=0$

Table 3 Kinetic constants for domestic coke-sample No. 9 in Table S2

\begin{tabular}{lllllrrr}
\hline Temperature/K & $\begin{array}{l}C \\
\text { acc. (18) }\end{array}$ & $k_{3}, \mathrm{~h}^{-1}$ & $k_{1}+k_{-1}$ & $R^{2}$ & Ratio & $\begin{array}{c}k_{1}^{*}, \mathrm{~h}^{-1} \\
\text { acc. }(20)\end{array}$ \\
\hline 1173 & 0.3035 & 0.1441 & 1.9708 & 0.8260 & 602.9 & 0.5544 \\
1223 & 0.5749 & 0.2635 & 2.0904 & 0.9228 & 950.9 & 1.0503 \\
1273 & 0.9559 & 0.4359 & 2.0247 & 0.9728 & 1313.6 & 1.5187 \\
1323 & 1.5954 & 0.5310 & 1.6836 & 0.9424 & 493.4 & 1.6164 \\
1373 & 1.6566 & 0.6087 & 2.3735 & 0.9969 & 6393.6 & 2.3735 \\
1423 & 2.7085 & 0.8046 & 1.9770 & 0.9983 & 9004.3 & 1.9701 \\
\hline
\end{tabular}

$*$ For $C>1, k_{-1}=0$

existence of three kinetic constants is confirmed: $k_{1}-\mathrm{a}$ relatively fast chemical reaction, $k_{-1}$-its reversible reaction and $k_{3}$ - the desorption process.

Relationships between the above-mentioned kinetic constants for the gasification process can be linear, as in the case of relation $k_{-1}$ versus $k_{3}$ :

$k_{-1}=-1.711 k_{3}+1.675 \quad\left(r^{2}=0.5771, \mathrm{sl}=0.0067\right)$.
This result means that in the absence of the desorption process, the kinetic constant of the reverse reaction is large $\left(k_{-1}=1.675 \mathrm{~h}^{-1}\right)$ and its value is always greater than the kinetic constant of the gasification reaction $\left(k_{-1}>k_{1}\right)$, which is acceptable in the context of the results presented in Table 1. For $k_{3}=0$, Eq. (18) reduces to the form of Eq. (15) with a horizontal asymptote, whose value follows from Eq. (19). 
However, relationships between the constants $k_{1}$ and $k_{-1}$ are curvilinear:

$$
\begin{aligned}
k_{1}= & -3.447+9.568 k_{-1} \\
& -5.295\left(k_{-1}\right)^{2}\left(R^{2}=0.6827 ; F=8.607 ; \mathrm{sl}=0.0101\right)
\end{aligned}
$$

which cannot be regarded as a strict analytical form. Inverting the variable arrangement, it should be noted that both small and larger values of $k_{-1}$ can be expected with the increase in $k_{1}$, which means that the relationship:

$C_{0}=\frac{k_{1}}{k_{1}+k_{-1}}$

is variable, e.g., for identical or similar values of $k_{1}$, and when $k_{-1} \rightarrow 0$, the relation $C_{0}$ is close to 1 . This variability is a very advantageous phenomenon from a technological point of view, whereas if $k_{-1}>k_{1}, C_{0}$ is explicitly $<1$.

Comparison of the values of the kinetic constant $k_{3}$ determined using Eq. (18) and (28) in the form of Eq. (29) indicates the absence of a two-parameter linear relationship. Dependence between these values has a linear form without an intercept $\left[\rho^{2}=0.9910, \mathrm{sl}=0.0(4)\right]$. The average value of $k_{3}$ from Eq. (28) is $32.5 \%$ smaller than the values from Eq. (18).

The final step of the comparative analysis is comparison of the kinetic constants given in formula (19) omitting the $k_{3}$ constant $\left(k_{3}=0\right)$ with the values determined from Eq. (28), defined as $C_{1}$ in Eq. (29) in the common graph (Fig. 2). Based on Fig. 2, it can be assumed that the compared kinetic constants determined on the basis of two different models are identical.

Comparison of kinetic constants according to Eqs. (18) and (28) indicates on the necessity of consideration of the reverse reaction in the calculations, known as the Bell reaction [22], although the kinetic constant of this reaction should tend toward 0 with increasing

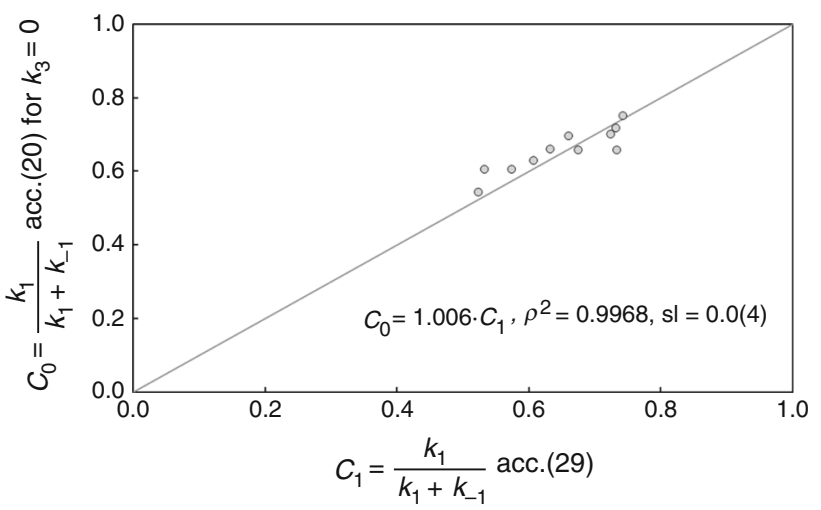

Fig. 2 Comparison of kinetic constants obtained from two different models temperature $\left(k_{-1} \rightarrow 0\right)$. Literature also suggests an inhibitory effect of $\mathrm{CO}$ disappearing with an increase in temperature [15].

It should be noted that association of the two elements of this complex gasification process, consisting of a reversible chemical reaction and the desorption process, is based on a balance of rates presented in formula (12). While this assumption allows for the improved description of the gasification process, deviations from this principle are known in the case of cokes.

\section{Effect of temperature}

Two samples of cokes were used in the analysis: blastfurnace coke (high quality)_-Table S2, No. 3 and domestic coke (low quality)_-Table S2, No. 9.

As expected, it was observed that with increasing temperature in the range $T=1173-1423 \mathrm{~K}$ (with step $\Delta T=50 \mathrm{~K})$ :

a. the reaction/process passes from a kinetic to a diffusion area; in both cases, for $T \geq 1323 \mathrm{~K}\left(1050{ }^{\circ} \mathrm{C}\right)$, kinetic constant $k_{1}$ changes slower than is predicted by Arrhenius's law,

b. the reverse reaction or inhibition effect of $\mathrm{CO}$ disappears, i.e., $k_{-1}=0$, and, as a consequence of the inequality (22) and the combination of kinetic constants $C>1, k_{-1}$ decreases and disappears as temperature increases, while the enthalpy of the disproportionation reaction (Bell reaction, $2 \mathrm{CO}=\mathrm{CO}_{2}+\mathrm{C}_{\mathrm{cb}}$ ) can be determined from the relation $\ln \left(k_{-1}\right)$ versus $1 / T$, and

c. for the reverse reaction, $k_{-1}=0$; hence, Eq. (18) simplifies, and Eq. (28) ceases to apply although it is directly compatible with Eq. (29) wherein the constant $C_{1}=[\mathrm{CO}]_{\mathrm{m}} \exp \left(k_{3} \tau_{\mathrm{m}}\right), 0<[\mathrm{CO}]_{\mathrm{m}} \leq 1$ becomes an empirical expression.

The above observations with the determined values of the activation energy and enthalpy for the mechanism of reaction (1) are shown in Figs. 3 and 4.

\section{Discussion}

Gasification with carbon dioxide of different carriers of carbon with low content of volatile matter $\left(\mathrm{MV}^{\text {daf }} \sim 0.8-2.0 \%\right)$ demonstrates their variable reactivity from easiest to the most resistant. The following order is generally assumed: carbonizates derived from brown coals $\rightarrow$ carbonizates from hard coals $\rightarrow$ domestic coke $\rightarrow$ blast-furnace coke $\rightarrow$ graphite.

The considerations in this paper are an extension of the finite time method for the determination of kinetic 
(a)

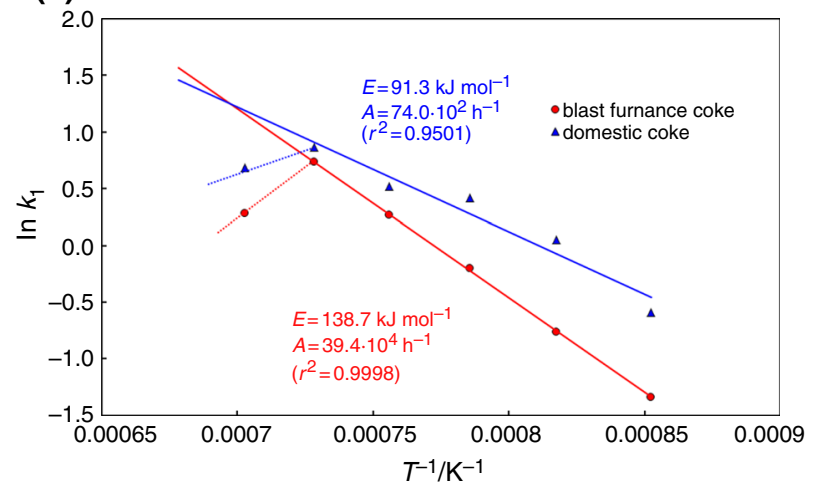

(b)

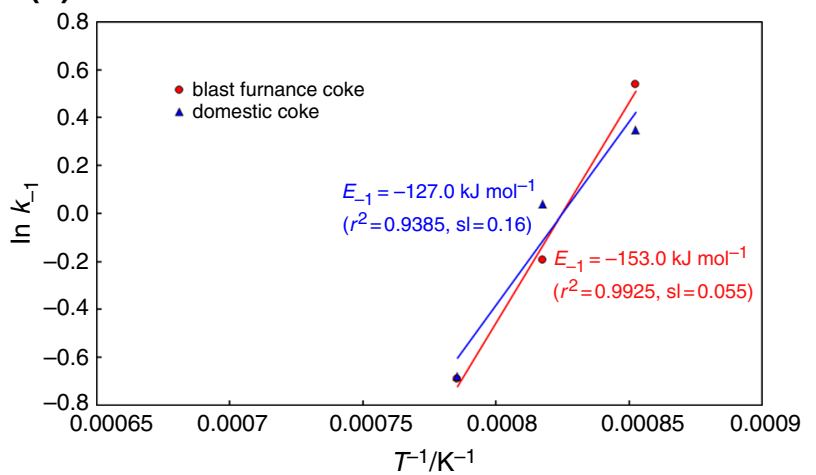

(c)

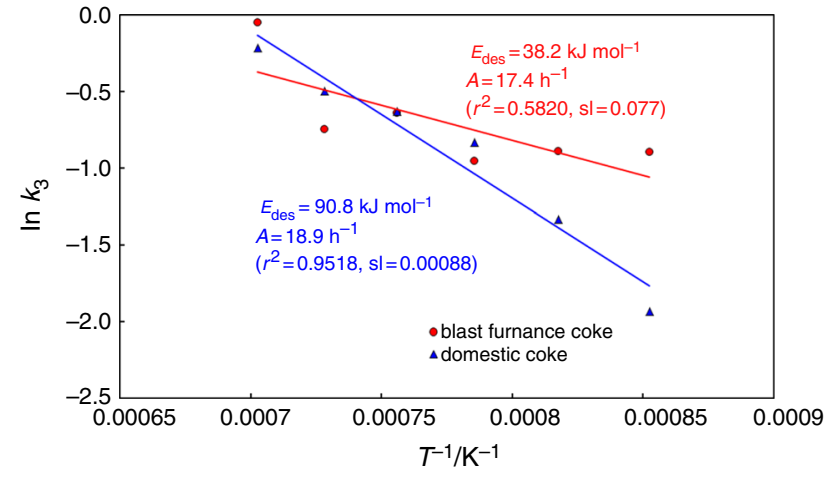

Fig. 3 Characteristic parameters of partial processes determined from the kinetic constants for the two coke samples-blast-furnace and domestic coke (Nos. 3 and 9 in Table S2)

parameters of a reaction/process [28]. The finite time method establishes that the conversion degree of a solid phase monotonically tends to 1 , not taking into account complexity of the gasification process. Coal gasification with carbon dioxide is a complex process, which comprises not only a reversible chemical reaction of gasification, but also a desorption process and an inhibiting effect of carbon monoxide.

This paper relates kinetic modeling of a Boudouard-Bell reaction for selected types of coke [26] on the basis of measurements taken in an apparatus for reactivity testing that uses the Geneva method [27].

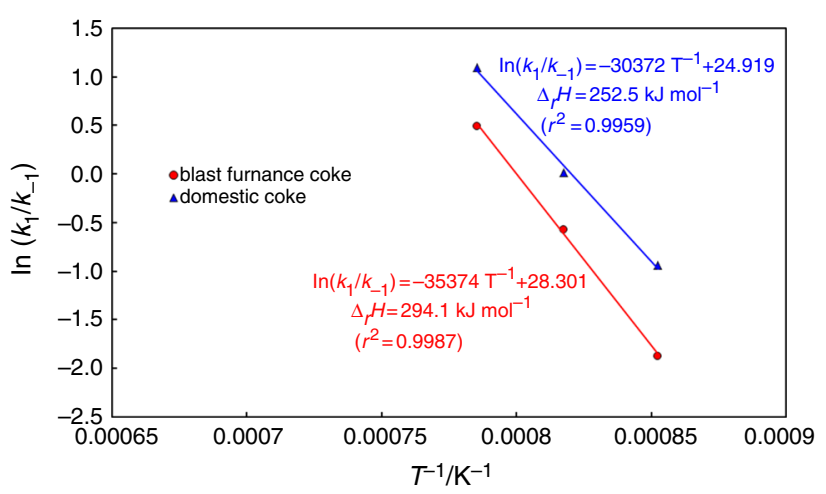

Fig. 4 Characteristics of reaction (1) by ratio $k_{1} / k_{-1}$

For this purpose, Eq. (18) is proposed, which contrary to several works on this subject $[22,23,26]$ is based on three kinetic constants. This basis allows for the determination of values characteristic to the processes (symbols are given in parentheses):

a. $k_{1}$ relates to Boudouard reaction (E) - Fig. 3a,

b. $k_{-1}$ characterizes Bell reaction $\left(E_{-1}\right)$-Fig. 3b,

c. $k_{3}$ is associated with desorption process $\left(E_{\mathrm{des}}\right)$ Fig. 3c,

and

d. ratio $k_{1} / k_{-1}$ characterizes B-B reaction (1) according to Ergun's concept [1] in form (6) $\left(\Delta_{\mathrm{r}} H\right)$-Fig. 4.

Section d) requires the specific comment. The Bell reaction, which is reverse to the Boudouard reaction, is analyzed as shown in Fig. $3 \mathrm{~b}$. The kinetic constant $k_{-1}$ tends to 0 with temperature increase, so the typical Arrhenius equation changes course, and formally negative value of the activation energy is obtained. One can find the negative activation energies as a result in the literature (Table 7 in [29]; p. 125 in [30]). To eliminate this problem, it is convenient to introduce the classical equation in the differential form with double using of conventional Arrhenius equation and both sides of the equation subtract from each other. Finally, one can obtain:

$\frac{\mathrm{d} \ln \left(\frac{k_{1}}{k_{-1}}\right)}{\mathrm{d} T}=\frac{E-E_{-1}}{R T^{2}}$

Equation (33) according to (6) is identical to the van't Hoff's isobar:

$\frac{\mathrm{d} \ln \left(\frac{k_{1}}{k_{-1}}\right)}{\mathrm{d} T}=\frac{\Delta_{\mathrm{r}} H}{R T^{2}}$

Consequently, the dependence $\ln \left(\frac{k_{1}}{k_{-1}}\right)$ versus $1 / T$ allows to determine the enthalpy of reaction (1).

The high values of $\Delta_{\mathrm{r}} H$ obtained in current studies require the specific comment. According to the 
thermodynamic data presented in Barin's tables [31], the enthalpy of reaction (1) for the hexagonal graphite equals $172.8 \mathrm{~kJ} \mathrm{~mol}^{-1}(298 \mathrm{~K} \leq T \leq 1400 \mathrm{~K})$, and the standard enthalpy $(298 \mathrm{~K})$ is similar $\left(172.5 \mathrm{~kJ} \mathrm{~mol}^{-1}\right.$ [22]). Marchon [32] cites a value of $180 \mathrm{~kJ} \mathrm{~mol}^{-1}$ for experiments at high pressure, but these data relate to reaction at the finite time $\left(\mathrm{C}+\mathrm{CO}_{2}=2 \mathrm{CO}\right)$. Ergun $[1,2]$ gives the enthalpy values much lower, i.e., $71.2-96.3 \mathrm{~kJ} \mathrm{~mol}^{-1}$ for carbonaceous substances with a high specific surface area (carbon black Spheron 6, activated carbons, etc.). The values $\Delta_{\mathrm{r}} H=252.5-294.1 \mathrm{~kJ} \mathrm{~mol}^{-1}$ obtained in this work relate to cokes, which are low reactive in the process according to Eq. 1.

Equation (18) was derived from the mechanism of the reaction/process (1) and (2) proposed by Ergun in 1956 [1], but using a different kinetic approach. In this case, the experimental observation is $\mathrm{CO}$ formation over time under $\mathrm{CO}_{2}$ flow through a fixed bed of coke. Equation (18) is characteristic for consecutive reactions exhibiting a maximum as a result of impact of an intermediate product: It forms and disappears. However, according to

(a)

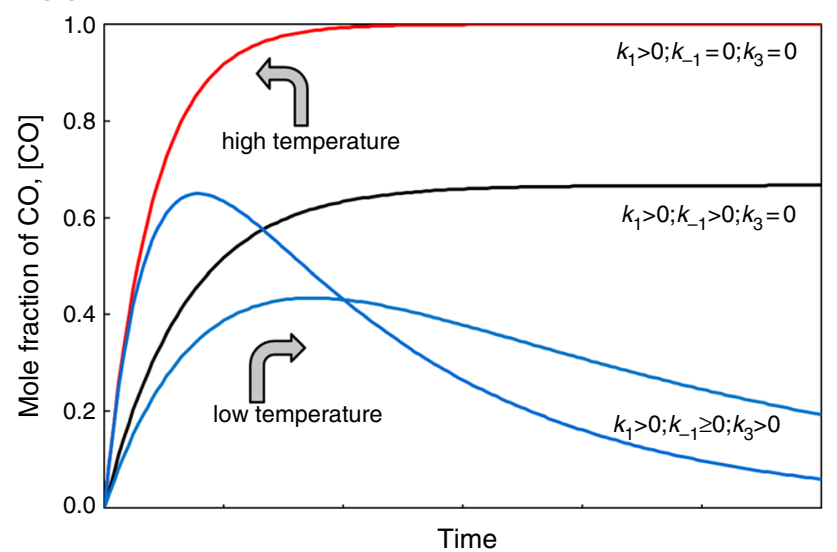

(b)

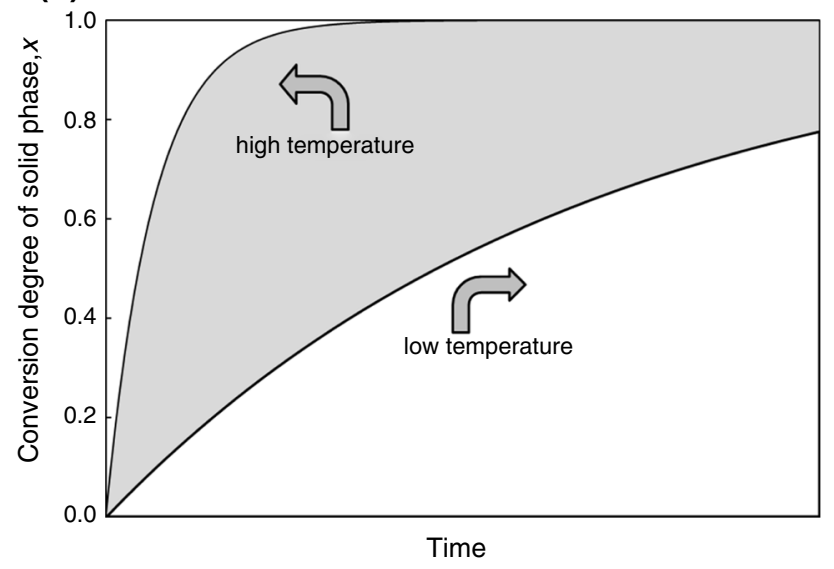

Fig. 5 Typical kinetic relations [CO] versus time (a), and $x$ versus time (b) for $\mathrm{CO}_{2}$ gasification process mechanism (1) and (2), Eq. (18) is the result of assumption (12) and two rates: that describing the chemical reaction and the desorption, and does not designate the share of intermediate product-oxy-carbon $\mathrm{C}(\mathrm{O})$. Difficulties related to the interpretation are founded in proposed enrichment of the mechanism presented in [1] by taking into account the existence of two intermediate states [23] (comment in Supplementary Materials).

Partial approximation of the primary Eq. (18) in form (28) was also introduced, which for the disappearance of the reverse reaction $k_{-1}=0$ is disengaged with the constants in Eq. (18), although it is still an exponential relation (29) and directly defines the kinetic constant $k_{3}$ with acceptable precision.

\section{Short summary}

Recent studies on $\mathrm{CO}_{2}$ gasification confirmed that the kinetic description of the process based on the composition of gaseous products is more complicated when compared with one based on the composition of a solid phase $[6,7,28]$. Three typical relations of [CO] versus time depending on temperature and relationships between kinetic constants of the reactions are shown in Fig. 5a. In the case of the solid phase, a consequent increase in conversion degree is observed (Fig. 5b).

\section{Conclusions}

1. The kinetic model (18) for the Boudouard-Bell reaction under isothermal conditions was proposed and is based on the combination of three kinetic constants: $k_{1}$ - the relatively rapid gasification reaction called the Boudouard reaction, $k_{-1}$-the disproportionation reaction called the Bell and $k_{3}$-the $\mathrm{CO}$ desorption process. From a mathematical point of view, Eq. (18) is characteristic for consecutive reactions and describes the kinetics of formation and disappearance of an intermediate product. In this case, Eq. (18) describes formation of the final product, i.e., CO.

2. The results forming Eq. (18) can be used in a simplified form (28) or (29) to determine the kinetic constants of the desorption process $k_{3}$ with acceptable precision.

3. Kinetic constants in the temperature range $T=1173-1423 \mathrm{~K}$ for two completely different types of cokes confirm the mode by which the reaction/ process progresses: from kinetic at low temperatures, through an intermediate and finally to diffusion mode at high temperatures. The estimated temperature of this effect is $1273 \mathrm{~K}\left(1050{ }^{\circ} \mathrm{C}\right)$ and is accompanied by the 
disappearance of the disproportionation reaction and inhibition effects, i.e., $k_{-1} \rightarrow 0$.

4. Kinetic constants of the desorption process $k_{3}$ fulfill Arrhenius's law. If in Eq. (18) and consequently in Eq. (20) $k_{-1}=0$, then increase in $k_{1}$ is associated with $k_{3}$ increase in the exponential Eq. (29), and the preexponential constant in Eq. (28) is converted to an empirical value.

Acknowledgements The research results presented herein were obtained during the course of the project "Development of coal gasification technology for high-efficiency production of fuel and energy." Task No. 3 of Strategic Program for Research and Development: "Advanced energy generation technologies" founded by the Polish National Center for Research and Development.

Open Access This article is distributed under the terms of the Creative Commons Attribution 4.0 International License (http:// creativecommons.org/licenses/by/4.0/), which permits unrestricted use, distribution, and reproduction in any medium, provided you give appropriate credit to the original author(s) and the source, provide a link to the Creative Commons license, and indicate if changes were made.

\section{References}

1. Ergun S. Kinetics of the reaction of carbon dioxide with carbon. J Phys Chem. 1956;60:480-5.

2. Mentser M, Ergun S. Kinetics of oxygen exchange between $\mathrm{CO}_{2}$ and CO on carbon. Carbon. 1967;5:331-7.

3. Rao MB, Vastola FJ, Walker PL Jr. Use of oxygen isotope exchange in $\mathrm{CO}_{2}$ to characterize active sites. Carbon. 1983;21:401-7.

4. Laurendal NM. Heterogeneous kinetics of coal char gasification and combustion. Prog Energy Combust Sci. 1978;4:221-70.

5. Aderibigbe DA, Szekely J. The temperature dependence of the rate constants $K_{1}, K_{2}$ and $K_{3}$ in the Langmuir-Hinshelwood rate relation for carbon-carbon dioxide reaction. Carbon. 1979;17:431-3.

6. Koenig PC, Squres RG, Laurendeau NM. Evidence for two-site model of char gasification by carbon dioxide. Carbon. 1985;23:531-6.

7. Calo JM, Perkins MA. Heterogeneous surface model for the "steady-state" kinetics of the Boudouard reaction. Carbon. 1987;25:395-407.

8. Freund $\mathrm{H}$. The kinetics of carbon gasification by $\mathrm{CO}_{2}$. Fuel. 1985;64:657-60.

9. Koenig PC, Squres RG, Laurendeau NM. Char gasification by carbon dioxide. Fuel. 1986;65:412-6.

10. Hüttinger KJ, Nill JS. A method for the determination of active sites and true activation energies in carbon gasification: (II) Experimental results. Carbon. 1990;28:457-65.

11. Hüttinger KJ, Fritz OW. The carbon-carbon dioxide reaction: an extended treatment of the active-site concept. Carbon. 1991;29:1113-8.
12. Feng B, Bhatia SK. On the validity of thermogravimetric determination of carbon gasification kinetics. Chem Eng Sci. 2002;57:2907-20.

13. Roberts DG. Intrinsic reaction kinetics of coal chars with oxygen, carbon dioxide and steam at elevated pressures. Ph.D. Thesis. Dep Chem Eng. University of Newcastle. 2000.

14. Roberts DG, Harris DJ. A kinetic analysis of coal char gasification reactions at high pressures. Energy Fuels. 2006;20:2314-20.

15. Roberts DG, Harris DJ. High-pressure char gasification kinetics: $\mathrm{CO}$ inhibition of the $\mathrm{C}-\mathrm{CO}_{2}$ reaction. Energy Fuels. 2012;26:176-84.

16. Liu G, Tate AG, Bryant GW, Wall TF. Mathematical modeling of coal char reactivity with $\mathrm{CO}_{2}$ at high pressures and temperatures. Fuel. 2000;79:1145-54.

17. Hurt RH, Calo JM. Semi-global intrinsic kinetics for char combustion modeling. Combust Flame. 2001;125:1138-49.

18. Niksa S, Liu G, Hurt RH. Coal conversion submodels for design applications at elevated pressures. Part I. Devolatilization and char oxidation. Prog Energy Combust Sci. 2003;29:425-77.

19. Liu G, Niksa S. Coal conversion submodels for design applications at elevated pressures. Part II. Char gasification. Prog Energy Combust Sci. 2004;30:679-717.

20. Saucedo MA, Lim JY, Dennis JS, Scott SA. $\mathrm{CO}_{2}$-gasification of lignite coal in the presence of an iron-based oxygen carrier for chemical-looping combustion. Fuel. 2014;127:186-201.

21. Radovic LR, Jiang H, Lizzio AA. A transient kinetics study of char gasification in carbon dioxide and oxygen. Energy Fuels. 1991;5:68-74.

22. Mianowski A, Robak Z, Tomaszewicz M, Stelmach S. The Boudouard-Bell reaction analysis under high pressure. J Therm Anal Calorim. 2012;110:93-102.

23. Shelef M, Walker PL Jr. Transient phenomena in the gasification of graphite by high-purity carbon dioxide. Carbon. 1967;5:93-105.

24. House JE. Principles of chemical kinetics. 2nd ed. Amsterdam: Elsevier; 2007.

25. Vyazovkin S, Linert W. Kinetic analysis of reversible thermal decomposition of solids. Int J Chem Kinet. 1995;27:73-84.

26. Słomska I. Criterion of the evaluation of coke reactivity in the presence of carbon dioxide. AGH No. 414. Kraków; 1973 (in Polish).

27. ECE-Verfahren: Doc.Coal/UWP/Working paper 1962, No. 41, der Europäischen Wirtschaftskommision (ECE), op.cit: Hermann W. Coke reactivity and coke strength. Part 1: coke reactivitysummary and outlook. Cokemaking Int. 2002;14:18-31.

28. Mianowski A, Tomaszewicz M, Siudyga T, Radko T. Estimation of kinetic parameters based on finite time of reaction/process: thermogravimetric studies at isothermal and dynamic conditions. React Kinet Mech Catal. 2014;111:45-69.

29. Wu P. The kinetics of reaction of carbon with carbon dioxide. $\mathrm{Ph}$. Thesis. Massachusetts Institute of Technology. 1949.

30. Johnson JL. Kinetics of coal gasification. New York: Wiley; 1979.

31. Barin I. Thermochemical data of pure substances, vol. 1. Weinheim: VCH Verlagsgesellschaft; 1989.

32. Marchon B, Tysoe WT, Carrazza J, Heinemann H, Somorjai GA. Reactive and kinetic properties of carbon monoxide and carbon dioxide on a graphite surface. J Phys Chem. 1988;92:5744-9. 